\title{
Hepatoprotective effect of hypoxenum against exogenous toxicosis of white rats
}

\author{
Aleksei Reznichenko*, Svetlana Vodianitskaia, Iana Masalykina, and Andrei Manokhin \\ Belgorod State Agricultural University named after V.Y. Gorin, Belgorod, 308503, Russia
}

\begin{abstract}
Any disturbances in the organism caused by infection, drug administration, vaccination, etc., are accompanied with disturbance of liver functions. Various xenobiotics entering animal organisms with food or water have the highest hepatotoxicity. Thus, an important trend in modern research is a search for substances increasing liver capacity against pathological activities, strengthening its detergent actions. The goal of this research was to study hepatoprotector properties of hypoxenum using the experimental acute toxic hepatitis model in white rats. The acute toxic hepatitis was caused by injecting the rats abdominally with tetrachloromethane in medical paraffin at a dose of $0.4 \mathrm{ml}$ per $100 \mathrm{~g}$ of live weight once a day for 3 days. This resulted in disturbance of hepatocytes' cytoplasmic membranes, accompanied with an increased rate of transamination enzymes and alkaline phosphotase, as well as an acute drop in glucose and total protein. Administration of hypoxenum stopped this pathological process. After the administration of the preparation, the animal's body weight increased, activity of transamination enzymes and alkaline phosphotase returned to physiological norm, protein and glucose content increased, general physiological condition of the white rats improved. Thus, hypoxenum may be administered to animals as a hepatoprotector at a dose of $50.0 \mathrm{mg} / \mathrm{kg}$ of live weight.
\end{abstract}

\section{Introduction}

Currently, there is an active ongoing search for substances increasing liver capacity against pathological activities, strengthening its detergent actions. The most commonly, liver damage is observed in large farms where high concentration of animals requires continuous use of antibacterial preparations, vaccines and other drugs aimed at preventing development of infectious diseases in animals $[1,2]$.

Multiplicity of liver functions leads to the fact that a disturbance in any kind of metabolism affects this organ, leading to cell damage and development of a new, more severe pathological process or complicating the main condition.

Recently, negative impact of a number of medical preparations on liver was discovered, whose hepatotoxicity acutely increases with their biotransformation due to formation of active metabolites. It has been established that poisoning with xenobiotics and metabolites of hormones and proteins accumulated in the body causes toxicosis and promotes increased intensity of lipid peroxidation (LPO).

Hepatoprotective effect may be seen from preparations that improve metabolic processes in the body, as well as those inhibiting lipid peroxidation and having antihypoxic activity [3,4].

Studies of toxic damage to liver attracted attention from many scientists [5-7]. Their general opinion is that deep dystrophic changes in the liver appear under the influence of hepatotoxic factors against the background of deficiency of biologically active substances. In particular, toxic substances entering the body with food and being formed inside the body due to indigestion and disturbance of intermediary metabolism have direct influence on hepatocytes when they find their way into blood and reach the animal's liver. Depending on the amount and duration of their admission to the organ's parenchyma, activity of oxidizing enzymes reduces, glycogen level drops sharply, fatty liver infiltration develops, cytolysis of liver cells with subsequent necrosis are observed. Excessive accumulation of toxins in the body and inability of physiological detoxification systems to ensure their effective removal lead to endogenic intoxication $[8,9]$.

According to S.B. Matveev, medium molecular weight substances are universal biochemical markers of endogenic toxicosis. Such substances are represented by intermediate and end products of normal and disrupted protein and lipid metabolism; they accumulate in the body in amounts exceeding normal concentrations and are products of free radical lipid peroxidation, intermediary metabolism, medium molecular weight peptides [10].

In case of liver damage independent of its etiology, the leading pathomorphological symptom is structural cell damage, leading to increased permeability and (or) destruction of hepatocyte membranes and membrabes of various organellas, development of hyperenzymemia of

* Corresponding author: reznichenko6531@gmail.com 
mitochondrial enzyme aspartate aminotransferase and cytoplasmic enzyme alanine aminotransferase [11].

In recent years, a strong case has been presented for the fact that lipid peroxidation processes is an important mechanism in hepatocyte damage and/or progression of chronic diffuse liver diseases. Currently, there is an active ongoing search for substances increasing liver capacity against pathological activities, strengthening its detergent actions by means of increasing the activity of cytolytic enzymes and cytochrome P-450, facilitating restoration of liver functions after various damages [12].

Hepatoprotective effect may be seen from preparations that improve metabolic processes in the body, as well as those inhibiting lipid peroxidation and having antihypoxic activity [13].

Due to that, the authors tested hypoxenum, a preparation with antioxidant properties.

The goal of this research was to study hepatoprotective properties of hypoxenum using the experimental acute toxic hepatitis model in white rats.

The following tasks were involved in attaining the set goal:

- to induce toxic hepatitis in white rats by administration of tetrachloromethane;

- to establish hepatoprotective effect of hypoxenum and compare it with that of heptran.

\section{Material and method of analysis}

The acute toxic hepatitis was caused by injecting the rats abdominally with tetrachloromethane in medical paraffin at a dose of $0.4 \mathrm{ml}$ per $100 \mathrm{~g}$ of live weight once a day for 3 days [14].

Hypoxenum and heptran were employed for treatment of the animals.

Effectiveness of the preparations was evaluated by changes in body mass, clinical conditions of the white rats and biochemical indicators of blood serum; the latter were determined with biochemical analyzer.

Research data were subjected to mathematical processing according to N. A.Plokhinsky [15], calculating average values $(\mathrm{M})$, coefficients of variation (m) and significance test value (p). Differences were held significant at $\mathrm{p}<0.05$.

Hypoxenum (sodium salt of [poly-(2,5dyhydroxyphenylen)]-4-tiosulphonic acid) is a black powder, odorless or with a weak specific odor. The preparation is produced by Petrokhim (Belgorod, Russia).

Heptran is a complex preparation that has hepatoprotective and antistress activity, $1 \mathrm{ml}$ of heptran contains $50 \mathrm{mg}$ of carnitine, $200 \mathrm{mg}$ of magnesium sulphate, $220 \mathrm{mg}$ of sorbiton, $30 \mathrm{mg}$ of cyanocobalamine, $8 \mathrm{mg}$ of calcium pantotenate, $20 \mathrm{mg}$ of nicotineamid, auxiliary and forming substances.

\section{Test results and discussion}

Four groups of 6 white outbred male rats with a weight of 160-180 g each were selected for the experiment.

The first group was control, others were experimental ones. The first group did not receive any preparations (intact animals). The rats of the second, third and fourth group were administered with a $50 \%$ emulsion of tetrachloromethane in petroleum jelly by introperitoneal injection in a dose of $4.0 \mathrm{ml} / \mathrm{kg}$ of live weight for three days. Immediately after ending administration of tetrachloromethane, the animals in the third group were administered hypoxenum for 7 days, at a dose of 50 $\mathrm{mg} / \mathrm{kg}$ of live weight. The fourth group was administered heptran at a dose of $1 \mathrm{ml} / \mathrm{l}$ of water for the same period of time

The design of the experiment is shown in Table 1.

Table 1. Design of the experiment

\begin{tabular}{|c|c|c|c|}
\hline \multicolumn{2}{|c|}{ Groups } & $\begin{array}{c}\text { Administered } \\
\text { preparation }\end{array}$ & Amount of \\
\hline Control & 1 & - & $\begin{array}{c}4.0 \mathrm{ml} / \mathrm{kg} \text { of } \\
\text { live weight }\end{array}$ \\
\hline experimental & 2 & tetrachloromethane & $\begin{array}{c}50 \mathrm{mg} / \mathrm{kg} \text { of } \\
\text { live weight }\end{array}$ \\
\cline { 2 - 4 } & 3 & $\begin{array}{c}\text { hypoxenum }+ \\
\text { tetrachloromethane }\end{array}$ & $\begin{array}{c}1 \mathrm{ml} / \mathrm{l} \text { of } \\
\text { water }\end{array}$ \\
\cline { 2 - 4 } & 4 & $\begin{array}{c}\text { Heptran }+ \\
\text { tetrachloromethane }\end{array}$ & \multicolumn{2}{c}{} \\
\hline
\end{tabular}

Blood sampling took place on days 7 and 14 after the beginning of the experiment.

Body weight of the experimental animals (Table 2) was monitored before administration of tetrachloromethane, after finishing its administration, as well as in days 7 and 14 (end of the experiment).

Table 2. Changes in body weight of rats

\begin{tabular}{|c|c|c|c|c|}
\hline \multirow{2}{*}{ Indicators } & \multicolumn{3}{|c|}{ Groups } \\
\cline { 2 - 5 } & 1 & 2 & 3 & 4 \\
\cline { 2 - 5 } & Control & tetrachloromethane & $\begin{array}{c}\text { tetrachloromethane }+ \\
\text { hypoxenum }\end{array}$ & $\begin{array}{c}\text { tetrachloromethane }+ \\
\text { heptran }\end{array}$ \\
\hline $\begin{array}{c}\text { Before administering } \\
\text { tetrachloromethane, } \mathrm{g}\end{array}$ & $162.6 \pm 3.7$ & $164.2 \pm 4.1$ & $166.1 \pm 5.0$ & $163.2 \pm 3.8$ \\
\hline $\begin{array}{c}\text { After administering } \\
\text { tetrachloromethane, } \mathrm{g}\end{array}$ & $162.8 \pm 3.3$ & $157.3 \pm 2.8$ & $156.2 \pm 4.1$ & $154.2 \pm 3.1$ \\
\hline Day 7. & $173.1 \pm 2.9$ & $150.4 \pm 3.2$ & $167.7 \pm 3.9$ & $166.2 \pm 2.4$ \\
\hline Day 14, (before culling), g & $181.2 \pm 3.9$ & $157.4 \pm 3.1$ & $186.2 \pm 3.9$ & $180.1 \pm 2.9$ \\
\hline
\end{tabular}


From the data in the table, it is evident that a gradual decrease in weight began in the second group right after administration of tetrachloromethane. At that, its maximum values were reached in Day 7 of the experiment, witnessing to development of toxic hepatitis; after that, the body weight started a slow increase and by the end of the experiment, it was $4.1 \%$ lower than the initial values.

In the third experimental group, hypoxenum had a positive effect on animal organisms. So, administration of the preparation not only stopped reduction in weight of the animals after development of toxic hepatitis, but facilitated its increase - in the end of the experiment the weight of the animals exceeded the initial values by $12.2 \%$.

In the fourth experimental group, the body weight of the animals after administration of heptran exceeded the initial values by $10.3 \%$ by the end of the experiment, witnessing to hepatoprotective action of the preparation.

Biochemical indicators of the animal blood are given in Table 3.

Table 3. Biochemical parameters of rat blood

\begin{tabular}{|c|c|c|c|c|}
\hline \multirow[t]{3}{*}{ Indicators } & \multicolumn{4}{|c|}{ Groups } \\
\hline & 1 & 2 & 3 & 4 \\
\hline & Control & tetrachloromethane & $\begin{array}{c}\text { hypoxenum } \\
\text { tetrachloromethane }\end{array}$ & $\begin{array}{c}\text { Heptran }+ \\
\text { tetrachloromethane }\end{array}$ \\
\hline \multicolumn{5}{|c|}{7 days after administration of preparations } \\
\hline AST units/1 & $188.7 \pm 5.36$ & $222.6 \pm 5.36 * *$ & $193.6 \pm 5.44$ & $197.1 \pm 5.39$ \\
\hline AST units/l & $98.3 \pm 5.36$ & $119.1 \pm 5.21 *$ & $101.3 \pm 5.13$ & $104.4 \pm 5.43$ \\
\hline Albumines, g/l & $30.3 \pm 1.69$ & $29.7 \pm 1.89$ & $34.2 \pm 0.67$ & $33.8 \pm 1.89$ \\
\hline Total protein, $\mathrm{g} / 1$ & $67.6 \pm 1.23$ & $63.8 \pm 1.02 *$ & $69.8 \pm 1.37$ & $68.8 \pm 1.29$ \\
\hline Urea, $\mathrm{mmol} / \mathrm{l}$ & $6.74 \pm 0.57$ & $8.33 \pm 0.65$ & $6.69 \pm 0.73$ & $7.92 \pm 0.49$ \\
\hline Creatinine, mg/dl & $0.48 \pm 0.32$ & $0.59 \pm 0.35$ & $0.46 \pm 0.39$ & $0.49 \pm 0.38$ \\
\hline Bilirubin, mg/dl & $0.50 \pm 0.17$ & $0.72 \pm 0.19$ & $0.51 \pm 0.12$ & $0.53 \pm 0.14$ \\
\hline Cholesterol, mmol/l & $1.14 \pm 0.15$ & $1.69 \pm 0.16^{*}$ & $1.28 \pm 0.20$ & $1.32 \pm 0.21$ \\
\hline Glucose, mmol/l & $9.27 \pm 0.78$ & $6.24 \pm 0.82 *$ & $9.13 \pm 1.11$ & $9.24 \pm 0.97$ \\
\hline Alkaline phosphotase, units/l & $350.0 \pm 4.87$ & $392.9 \pm 4.89 * *$ & $352.6 \pm 5.18$ & $357.1 \pm 5.22$ \\
\hline \multicolumn{5}{|c|}{ In the end of the experiment } \\
\hline AST units/l & $178.7 \pm 6.32$ & $203.2 \pm 6.29 *$ & $180.9 \pm 6.89$ & $181.3 \pm 5.76$ \\
\hline AST units/l & $92.8 \pm 5.47$ & $109.6 \pm 5.58 *$ & $94.4 \pm 4.35$ & $97.6 \pm 5.29$ \\
\hline Albumines, g/l & $32.7 \pm 1.29$ & $30.4 \pm 0.96$ & $38.1 \pm 1.39^{*}$ & $36.7 \pm 1.14$ \\
\hline Total protein, g/l & $68.9 \pm 1.45$ & $66.0 \pm 1.58$ & $72.3 \pm 1.40$ & $72.7 \pm 1.51$ \\
\hline Urea, Mmol/1 & $6.79 \pm 0.57$ & $7.14 \pm 0.69$ & $6.47 \pm 0.64$ & $7.11 \pm 0.65$ \\
\hline Creatinine, $\mathrm{mg} / \mathrm{dl}$ & $0.48 \pm 0.22$ & $0.50 \pm 0.39$ & $0.54 \pm 0.31$ & $0.49 \pm 0.36$ \\
\hline Bilirubin, mg/dl & $0.56 \pm 0.19$ & $0.59 \pm 0.15$ & $0.53 \pm 0.09$ & $0.58 \pm 0.31$ \\
\hline Cholesterol, mmol/l & $1.23 \pm 0.26$ & $1.57 \pm 0.21$ & $1.27 \pm 0.23$ & $1.30 \pm 0.29$ \\
\hline Glucose, $\mathrm{Mmol} / \mathrm{l}$ & $9.26 \pm 0.98$ & $5.92 \pm 0.96^{*}$ & $9.97 \pm 1.11$ & $8.96 \pm 1.05$ \\
\hline Alkaline phosphotase, $\mathrm{u} / \mathrm{L}$ & $351.8 \pm 5.21$ & $380.0 \pm 4.96^{*}$ & $350.8 \pm 5.29$ & $357.3 \pm 5.49$ \\
\hline
\end{tabular}

Note $*-p<0.05$

From the data in the table, it is evident that administration of tetrachloromethane led to damage to cytoplasmic membranes of hepatocytes, reflected in an increased activity of transamination enzymes in blood serum: in the second group, 7 days after the administration, activity of aspartate aminotranspherase and alanine aminotranspherase increased by 17.9 and $21.1 \%$ respectively. In the end of the experiment, this increase amounted to 13.7 and $18.1 \%$, respectively (in all cases $\mathrm{p}<0.01-0.05)$.

As it is known, increased activity of transamination enzymes in blood serum is an objective indicator of damage to liver parenchyma. In healthy animals, enzyme concentration inside hepatocytes is significantly higher than in blood serum. When hepatocytes are damaged, this serum-cell gradient is acutely disrupted. Cytolysis of liver parenchyma is accompanied with increase in permeability of hepatocyte cell membranes and membranes of cell organellas; at that, cytoplasmic, mitochondrial and lysosomic enzymes are released in circulation [13].

Administration of hypoxenum stopped this pathological process. For instance, in the third experimental group, activity of aspartate aminotranspherase and alanine aminotranspherase increased only by 2.6 and $3.1 \%$ respectively on Day 7 of the experiment. By the end of the experiment, activity of these enzymes was increased by 1.7 and $1.8 \%$, however this difference with control was found to be statistically insignificant.

As for heptran, its activity was also effective throughout the experiment. For instance, on Day 7, there was an increase in activity of aspartate aminotranspherase and alanine aminotranspherase by 4.4 and $6.2 \%$. In the end of the experiment activity of these enzymes exceeded the controls by 1.5 and $5.2 \%$ (p>0.05).

After the rats were administered tetrachloromethane, in the second group there was observed a reduction of total protein content in the blood serum by $5.6 \%$ (Day 7) and by $4.2 \%$ (in the end of the experiment), however, only the change at Day 7 was statistically significant $(\mathrm{p}<0.05)$.

It means that tetrachloromethane disturbs metabolism of individual amino acids in the body. As it is well known, liver takes an active part in metabolism of 
methionine. When it is damaged, the mechanism of transsulfuration is disturbed, resulting in a reduced content of cysteine and glutathione in blood. The latter is an important link in the hepatocytes' antioxidant system. In case of $\mathrm{CCl}_{4}$-induced hepatitis, hypoproteinemia is observed as a result of inhibited protein synthesis and degradation of amino acids.

In the third and fourth experimental group, after administration of hypoxenum and heptran, the protein level was even somewhat high, however, these changes were not deemed statistically significant.

The research data demonstrate that the studied preparations normalize protein synthesis in liver parenchyma, previously inhibited in toxic hepatitis, improve deactivation of protein breakdown products, prevent development of endogenic toxicosis.

Administration of tetrachloromethane to rats caused a sharp reduction of glucose content in the blood serum of the animals in the second group by $32.7 \%$ by Day 7 and by $36.1 \%$ by Day 14 in comparison with controls. It means that development of the toxic hepatitis involves a hypoglycaemia against the background of a sharp drop in glycogen content in the liver as a result of inhibited glyconeogenesis and amplified glycogenolysis. At that, synthesis of insulinases that degrade insulin is disrupted.

After administration of hypoxenum in the third group, the glucose level first reduced somewhat (by $1.5 \%$ on Day 7) and increased by $7.6 \%$ in the end of the experiment. However, these changes were deemed statistically insignificant.

After administration of heptran, fluctuations of glucose content in blood serum were small and did not show statistical difference from control.

Thus, both preparations are effective in preventing development of hypoglycaemia.

As for alkaline phosphotase, after administration of tetrachloromethane, its content in blood serum of the second group of animals increased by $12.3 \%$ on the Day 7 and by $8.0 \%$ in the end of the experiment in comparison with the controls $(\mathrm{p}<0.05)$, witnessing to damaged liver parenchyma. As it is known, alkaline phosphotase is an excretory enzyme; it is a complex of isoenzymes of various tissues with prevalence of enzymes of liver, osseal and intestinal origin.

After administration of hypoxenum and heptran in third and fourth experimental groups, alkaline phosphotase was within the physiological norm and showed no practical difference from that of control animals.

Thus, the research confirmed that hypoxenum and heptran have a hepatoprotective action on animal organism. Both studied preparations arrested the development of a toxic hepatitis in rats, reflected in decrease in the level of transamination enzymes and alkaline phosphotase, and increase in the content of protein and glucose in blood serum. This is an evidence of restored functioning of hepatocytes and normalized functioning of the organism.

\section{Conclusion}

As a result of the research, hypoxenum may be recommended as an effective hepatoprotector preparation for farm animals. Recommended dosage is $50.0 \mathrm{mg} / \mathrm{kg}$ of live weight; recommended route of administration is with water.

\section{References}

1. A.A. Manokhin, L.V. Reznichenko, V.N. Karaichentsev, Annals of Kazan State Acad. of Veter. Med. named after N.E. Bauman, 232(4), 108-112 (2017)

2. P.-G. Pietta, Flavonoids as Antioxidants, J. of Natural Prod., 63(7), 1035-1042 (2000)

3. S.P. Kolesnichenko, F.K. Denisova, L.V. Reznichenko, N.A. Denisova, Annals of Kazan State Acad. of Veter. Med. named after N.E. Bauman, 232(4), 80-84 (Kazan, 2017)

4. S.P. Kolesnichenko, N.G. Savushkina, S.B. Noskov, Ia.P. Masalykina, Annals of Kazan State Acad. of Veter. Med. named after N.E. Bauman, 232(4), 85-88 (Kazan, 2017)

5. E.V. Kuzminova, Polytop. Electr. Sci. J. of Kuban State Agricult. Univer., 102, 787-797 (2014)

6. J.A. Olson, Vitamin A and carotene as antioxidant in a physiological context, J. Nutr. Sci. and Vitaminology (1993)

7. O.Iu. Katikova, Experim. and Clin. Pharmacol., 65(5), 53-56 (2002)

8. A.A. Reznichenko, V.I. Dorozhkin, D.L. Nikonkov, M.I. Chenikova, Ia.P. Masalykina, Veter. and Feed., 3, 13-15 (2019)

9. L. Reznichenko, O. Bykova, F. Denisova, S. Vodyanitskaia, R. Shcherbinin, Diets Int. J. of Advan. Bio-technol. and Res. (IJABR), 10(2), 560-566 (2019)

10. S.B. Matveev, N.F. Fedorova, M.A. Godkov, Clin. Labor. Diagn., 5, 16-18 (2009)

11. L.V. Reznichenko, S.B. Noskov, M.N. Penzeva, A.A. Manohin, Int. J. of Pharm. and Technol., 8(4), 26882-26888 (2016)

12. N. Yang, R.S. Jiang, World's Poultry Sc. J., 61, 373-381 (2005)

13. L.Iu. Ilchenko, T.I. Karlovich, Pharm., 8/9, 54-58 (2007)

14. A.I. Vengerovsky, Methodological guidelines for studying hepatoprotector activity of pharmaceutical substances, In: Manual for experimental (preclinical) studies of new pharmaceutical substances (Remedium, Moscow, 2000) pp. 228-231

15. N.A. Plokhinsky, Biometry (Moscow University, Moscow, 1987), 367 p. 